\title{
Progressive Electrocardiographic Changes in Arrhythmogenic Right Ventricular Cardiomyopathy
}

\author{
Masaki Ota, Yoshiaki Kaneko, Tadashi Nakajima and Masahiko Kurabayashi
}

Key words: arrhythmogenic right ventricular cardiomyopathy, epsilon wave

(Intern Med 50: 2241, 2011)

(DOI: 10.2169/internalmedicine.50.6037)
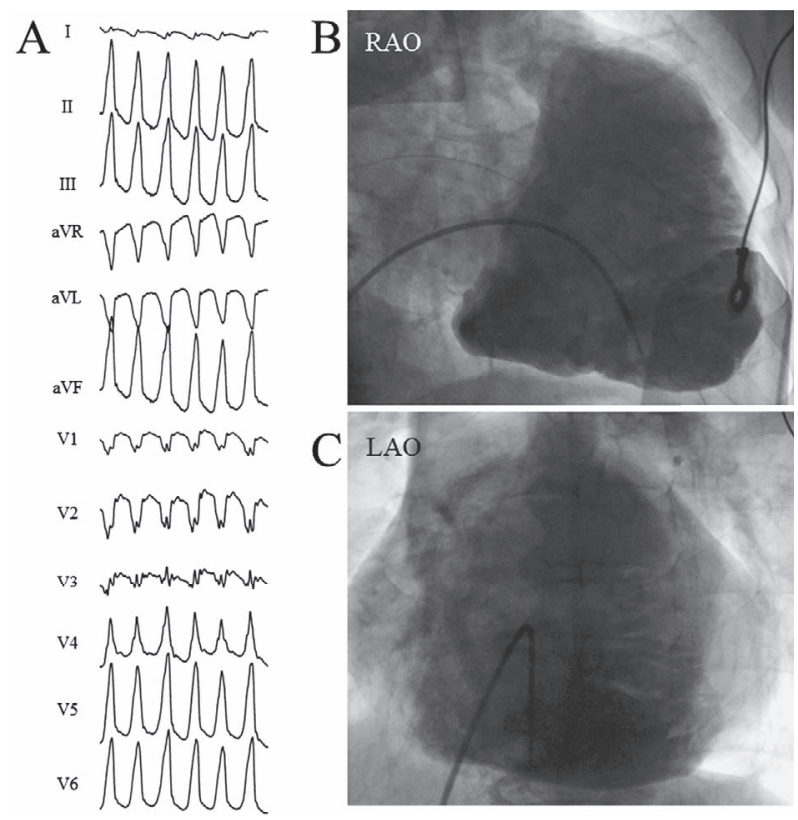

Picture 1.

A 77-year-old man was admitted to our hospital after the first episode of sustained ventricular tachycardia (VT) (Picture 1A). The 12-lead ECG during sinus rhythm showed typical epsilon waves (arrows) in the inferior and anterior precordial leads and inverted $\mathrm{T}$ waves in leads $\mathrm{V}_{1}$ to $\mathrm{V}_{5}$ (Picture 2C). A right ventriculogram showed right ventricular (RV) enlargement, moderate systolic dysfunction, and segmental dilatation of the anterior free wall (Picture $1 \mathrm{~B}$ and $\mathrm{C}$ ). Although histopathological examination of an endomyocardial biopsy of the RV free wall showed no fatty infiltration, 3 major and 1 minor criteria were fulfilled for confirming the diagnosis of arrhythmogenic RV cardiomyopathy (ARVC). Interestingly regarding morphology, in

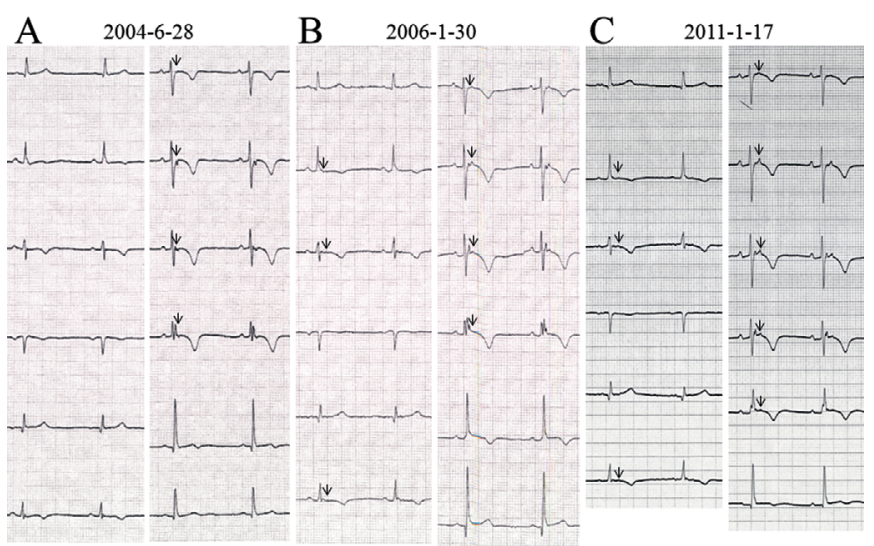

Picture 2.

the seven years prior to admission, epsilon waves (arrows) were progressively changed and there was an increase in the number of leads detecting those, and the timing compared to the QRS complex was progressively delayed (Picture 2). The present case presents a unique observation of the electrocardiographic changes preceding the new occurrence of VT in an old patient with $\operatorname{ARVC}(1,2)$, which may reflect the progressive pathological change which leads to the development of the arrhythmogenic substrate.

The authors state that they have no Conflict of Interest (COI).

\section{References}

1. Quarta G, Ward D, Tomé Esteban MT, et al. Dynamic electrocardiographic changes in patients with arrhythmogenic right ventricular cardiomyopathy. Heart 96: 516-522, 2010.

2. Piccini JP, Nasir K, Bomma C, et al. Electrocardiographic findings over time in arrhythmogenic right ventricular dysplasia/cardiomyopathy. Am J Cardiol 96: 122-126, 2005.

Department of Medicine and Biological Science, Gunma University Graduate School of Medicine, Japan

Received for publication June 21, 2011; Accepted for publication June 30, 2011

Correspondence to Dr. Yoshiaki Kaneko, kanekoy@gunma-u.ac.jp

(C) 2011 The Japanese Society of Internal Medicine Journal Website: http://www.naika.or.jp/imindex.html 